\title{
PEDESTRIAN RISK AT THE SIGNALIZED PEDESTRIAN CROSSING EQUIPPED WITH COUNTDOWN DISPLAY
}

\author{
Milan Vujanić ${ }^{1}$, Dalibor Pešić ${ }^{2}$, Boris Antić ${ }^{3}$, Emir Smailović ${ }^{4}$ \\ 1,2,3,4 University of Belgrade, Faculty of Traffic and Transport Engineering, Vojvode Stepe 305, 11000 \\ Belgrade, Serbia
}

Received 18 December 2013; accepted 12 February 2014

\begin{abstract}
In this paper we proposed method for assessing pedestrian risk at the signalized pedestrian crossing equipped with counter. Results showed that $17.5 \%$ of pedestrians were at high risk and male pedestrians are more often in dangerous situation (20.4\%) than female pedestrians $(14.4 \%)$. About $3 \%$ of all examined pedestrians created conflict situations, more frequently in first 5 seconds and last 5 seconds of red light phase (79.7\% of all offenders), but the risk that pedestrians will create a conflict situation were higher in other time of red light phase. Analysis of pedestrians' behavior at pedestrian crossings equipped with countdown display could point to potentially safety problems for pedestrians and those analysis could give direction for proposing and implementing adequate countermeasures. Also, numerically defined pedestrian accident risk could assess road safety level for pedestrians and show accident occurrence probability.
\end{abstract}

Keywords: pedestrian risk, signalized intersection, crosswalk, countdown display.

\section{Introduction}

Almost half number of killed in traffic accidents all around the world are vulnerable road users (WHO, 2009). Traffic accident costs of pedestrian accidents are very high, because of more severe consequences (Antić et al., 2011). According to strategies in the field of traffic safety, safety of the vulnerable road users (pedestrians, cyclists etc.) in traffic is one of the most important goals (Vujanić et al., 2013). Pedestrians are especially endangered at intersections, because of large number of traffic conflicts between vehicles and pedestrians. One of the useful measures for decreasing pedestrians' risk at the signalized pedestrian crossings is counting down display of the time for green or red light for pedestrians. According to
Martin (2006) countdown displays have advantages (easy to understand for all road users, easy to install, particularly suitable for wide pedestrian crossings, etc), but disadvantages as well (impossible to use by blind people, differences in the ways of counting down, etc).

Eccels et al. (2003) showed that the impact of countdown displays on the pedestrian behavior is positive, and that the displays don't have negative impacts on pedestrian behavior, and Singer and Lerner (2005) showed that displays have more positive impacts if the red light is not turned on at the same time with the counter. Counters were also researched by Druilhe and Khoudour (1987) and showed that additional information makes the remaining time

${ }^{3}$ Corresponding author: b.antic@sf.bg.ac.rs 
to wait more acceptable. However, Baass (1989) realized that this information may cause higher number of offences, when the remaining time to wait is too long, longer than 40 seconds. Guo et al. (2011) showed that the violation inclination of the most pedestrian increased with the increasing waiting duration, but about 10 percent of pedestrians were at high risk of violation to cross the street. Also, Guo et al. (2011) showed that about half of pedestrians would still obey the traffic rules even after waiting for $50 \mathrm{~s}$ by the street.

Martin (2006) also showed high number of red light crossings if waiting time is too long (38\% of pedestrians crossed during red light if waiting time was between 40 and 60 seconds, and only $18 \%$ if waiting time is less than 30 seconds). Allsbrook (1999) determined that pedestrians in USA have positive attitude towards device ( $92 \%$ of pedestrians considered that those signals are easier to understand). During the analysis of the pedestrian violations, Diaz (2002) came to the conclusion that young pedestrians are more likely to cross the streets at red light.

Huang and Zeeger (2000) researched two intersections with and three intersections without countdown displays, and results showed decreased percent of pedestrians who cross during red light from $59 \%$ to $47 \%$. The effects of the countdown devices were also analyzed by Keegan and O'Mahony (2003), by using video-monitoring of pedestrians' behavior at pedestrian crossings with and without countdown displays, as well as by doing the questionnaire with pedestrians who wait for the green light and with pedestrians who cross the street at red light. Conclusion was that because of display the number of pedestrians who cross during the red light was decreased from $35 \%$ to $24 \%$, and that the number of female offenders is lower as well as the number of pedestrians who did not at hurry. Similar research was conducted by Lipovac et al. (2013), where was analyzed pedestrian red light crossing at two pedestrian signalized crossings, one with and second without countdown display, and results showed less number of red light crossing pedestrians at crossings with countdown displays.

Concerning pedestrian behavior when they are alone or in a group, Rosenbloom (2009) showed that the number of males who cross the street during red light is higher than the number of females, but hypothesis about the higher probability of pedestrian crossing the street during red light if others are already crossing the street, compared to the probability that a pedestrian will start crossing the street when other pedestrians are waiting for the green light, was not confirmed.

Markowitz et al. (2006) researched pedestrian behavior before and after installing countdown displays, and results showed decreasing of the number of observed vehicle/pedestrian conflicts. Also, Pešić et al. (2012) showed decreasing number of accidents with pedestrians after implementing countdown displays.

This paper presents a research which was done in order to define the pedestrian behavior pattern at signalized crossings with countdown display, as well as to define the level of risk for pedestrians who cross the street at signalized intersections during red light. The research was done by monitoring pedestrian crossing using videotaping, and statistical methods were used to determine correlation of pedestrian red light crossing per gender, age, being in a group or alone, 
second after red light onset. The level of risk for traffic accident occurrence depending on conflict situations emerged during pedestrian red light crossing is also defined.

\section{Method and Materials}

In Serbia (Belgrade) pedestrian traffic lights have red and green light. The researched intersection (Fig. 1) with signalized pedestrian crossing equipped with countdown display is located in the center of Belgrade (Serbia). During survey, traffic flow per lane was over 1,500 vehicle/hour and pedestrian flow at pedestrian crossing was over 700 pedestrian/hour. Speed limit was $40 \mathrm{~km} / \mathrm{h}$. The cycle light lasted 80 seconds, and green light for pedestrians lasted "only" 10 seconds. This was main reason because we researched pedestrian crossing equipped with countdown display. While pedestrian flow was flowing over 700 pedestrians/ hour and the green light for pedestrians was shorting, we wanted to research, how is behavior of pedestrians at signalized crossing equipped with countdown display.

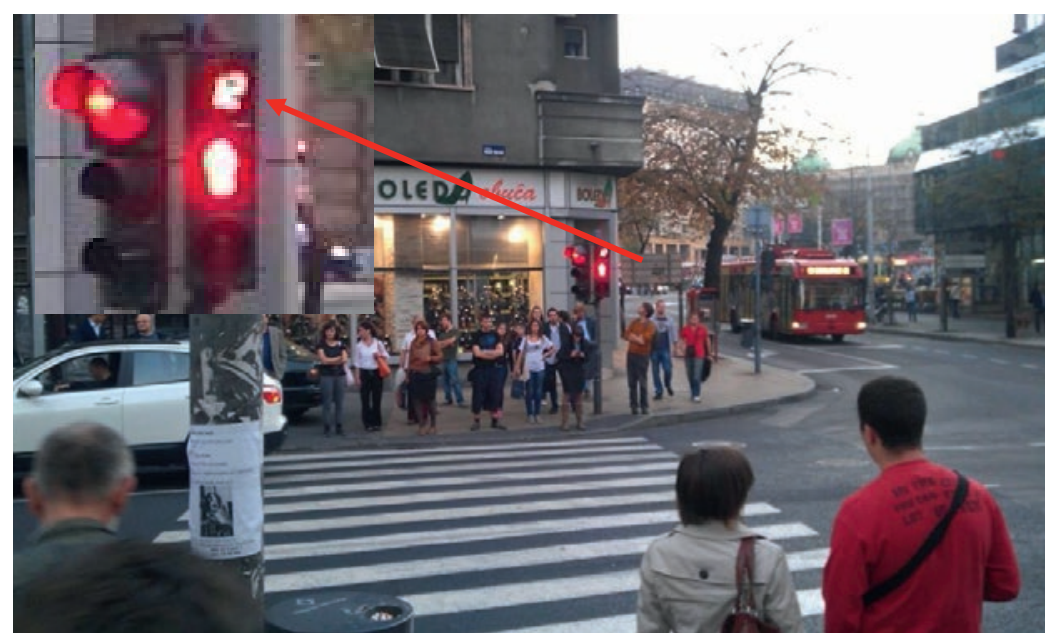

Fig. 1.

The Researched Location of Pedestrian Crossing

The survey of pedestrian crossing was conducted by digital camera, during a seven-day-period, from $06 / 06 / 2012$, until $06 / 12 / 2012$, one hour per day. The time of survey was around $6 \mathrm{pm}$, when pedestrian traffic flow was very intense. Camera recording was done discretely (hidden camera), so results could coincide with real conditions. Data about pedestrian behavior was gathered according to:
- non-offenders or offenders;

- second of pedestrians' crossing at the red light;

- the light at the start and at the end of crossing;

- the day of the week;

- gender;

- crossing as individual, in a couple or in a group (three or more pedestrians);

- age;

- conflict situation occurrence. 
Before starting to analyze gathered data, the red light interval for pedestrians was divided into $5 \mathrm{~s}$ intervals. Analyzes that covered statistically significant differences in the number of males and females who made red light crossing, in the number of male and female pedestrians by second after red light onset, in the number of male and female pedestrians who made conflict situations. Using descriptive statistics it was analyzed pedestrians' behavior which crossed during red light phase per age, per crossing alone, in a couple or in a group, etc. Also, for defining the risk of traffic accident occurrence, it was proposed that risk could be calculated as a rate between the number of conflict situations created during the red light crossings and the total number of offenders.

\section{Results}

Total number of pedestrians who crossed at the pedestrian crossing during survey period was $5109.17 .5 \%$ pedestrians has started crossing during the red light. Table 1 shows the number of pedestrians who are non-offenders and offenders by gender and by way of crossing (crossing alone, in a couple or in a group).

Table 1

The Number of Pedestrians who are Non-Offenders / Offenders by Gender and the Way of Crossing

\begin{tabular}{|c|c|c|c|c|c|c|c|c|c|}
\hline \multirow[b]{2}{*}{ Gender } & \multicolumn{4}{|c|}{ Non-offenders } & \multicolumn{4}{|c|}{ Offenders } & \multirow[b]{2}{*}{$\Sigma$} \\
\hline & $\stackrel{\Xi}{\stackrel{0}{0}}$ & نे & 올 & $\Sigma$ & $\frac{\ddot{z}}{\stackrel{0}{4}}$ & $\frac{0}{0}$ & 일 & $\Sigma$ & \\
\hline $\begin{array}{c}\text { Male } \\
(\%)\end{array}$ & $\begin{array}{c}1021 \\
(39.2 \%)\end{array}$ & $\begin{array}{c}859 \\
(32.9 \%)\end{array}$ & $\begin{array}{c}196 \\
(7.5 \%)\end{array}$ & $\begin{array}{c}2076 \\
(79.6 \%)\end{array}$ & $\begin{array}{c}331 \\
(12.7 \%)\end{array}$ & $\begin{array}{c}175 \\
(6.7 \%) \\
\end{array}$ & $\begin{array}{c}27 \\
(1 \%)\end{array}$ & $\begin{array}{c}533 \\
(20.4 \%) \\
\end{array}$ & $\begin{array}{c}2609 \\
(51.1 \%)\end{array}$ \\
\hline $\begin{array}{c}\text { Female } \\
(\%)\end{array}$ & $\begin{array}{c}885 \\
(35.4 \%) \\
\end{array}$ & $\begin{array}{c}1059 \\
(42.3 \%)\end{array}$ & $\begin{array}{c}197 \\
(7.9 \%) \\
\end{array}$ & $\begin{array}{c}2141 \\
(85.6 \%)\end{array}$ & $\begin{array}{c}184 \\
(7.4 \%) \\
\end{array}$ & $\begin{array}{c}147 \\
(5.9 \%)\end{array}$ & $\begin{array}{c}28 \\
(1.1 \%) \\
\end{array}$ & $\begin{array}{c}359 \\
(14.4 \%) \\
\end{array}$ & $\begin{array}{c}2500 \\
(48.9 \%)\end{array}$ \\
\hline $\begin{array}{c}\Sigma \\
(\%)\end{array}$ & $\begin{array}{c}1906 \\
(37.3 \%) \\
\end{array}$ & $\begin{array}{c}1918 \\
(37.5 \%)\end{array}$ & $\begin{array}{c}393 \\
(7.7 \%) \\
\end{array}$ & $\begin{array}{c}4217 \\
(82.5 \%) \\
\end{array}$ & $\begin{array}{c}515 \\
(10.1 \%)\end{array}$ & $\begin{array}{c}322 \\
(6.3 \%) \\
\end{array}$ & $\begin{array}{c}55 \\
(1.1 \%) \\
\end{array}$ & $\begin{array}{c}892 \\
(17.5 \%) \\
\end{array}$ & $\begin{array}{c}5109 \\
(100 \%)\end{array}$ \\
\hline
\end{tabular}

The analysis of the total number of males and females shows that there is no significant difference between the number of males or females $\left(\chi^{2}=2.32<\chi_{\alpha=0.05}^{2}=3.84 ; p \leq 0.05\right)$. On the other hand, the analysis of the number of males and females who crossed at red light, shows that there is a significant difference between males and females $\left(\chi^{2}=33.94>\chi_{\alpha=0.05}^{2}=3.84 ; p \leq 0.05\right), \quad \mathrm{m}$ a le s crossed more often at red light than females. Males are less patient than females when waiting for the green light. Pedestrians (both genders), when crossing at red light, usually do that while being alone.

Pedestrians usually cross at red light during the last seconds, or in the first seconds of red light (Fig. 2). In the first and in the last 5s of red light there was $79.7 \%$ of all offenders. The function line of the number of offenders has U shape, with two maximums, at the beginning and at the end of the red light phase (Fig. 2). Also, there is a significant difference between the number of males and females, concerning the second of crossing at red light $\left(\chi^{2}=27.71>\chi_{\alpha=0.05}^{2}=22.36 ; p \leq 0.05\right)$. 


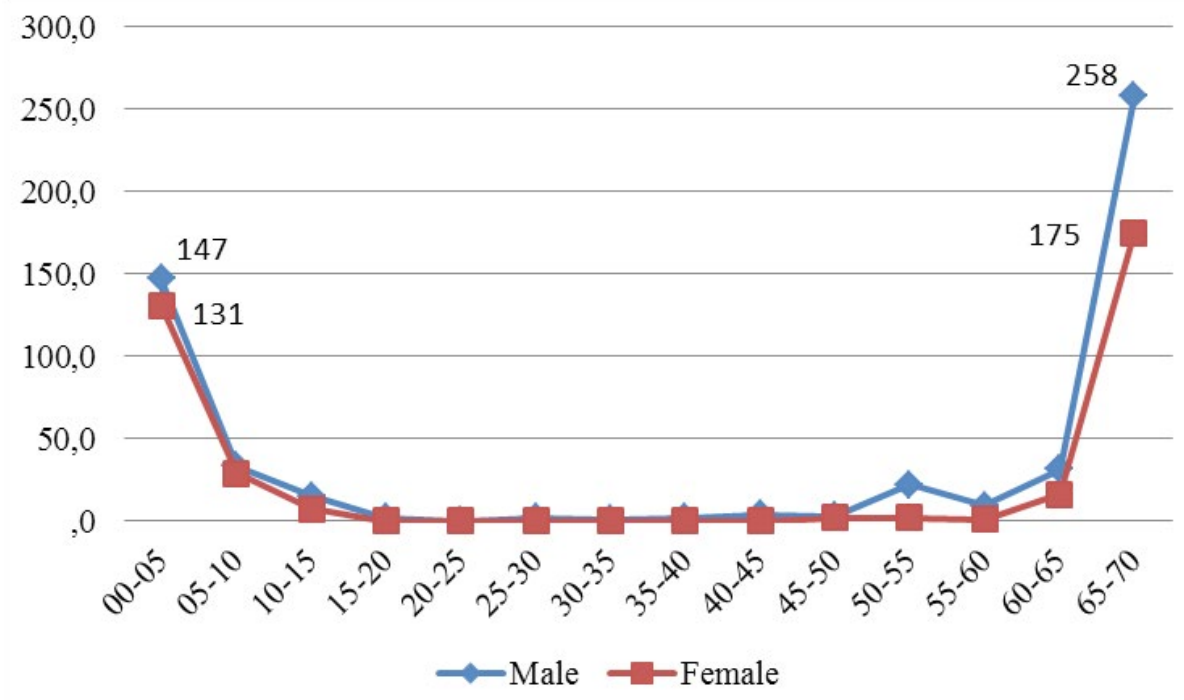

Fig. 2.

The Number of Offenders According to Gender and the Second of Crossing during Red Light Phase

According to estimated age (under 30, between 30 and 50, older than 50), the highest number of offenders of both genders is under the age of 30. In all three age groups, there are more male offenders.
Furthermore the analysis of pedestrian crossings and conflict vehicle/pedestrians, according to the light which was on at the beginning and the end of the crossing, is shown in Table 2.

\section{Table 2}

The Number of Pedestrians According to the Light on the Traffic Light and Conflicts Vehicle/Pedestrian

\begin{tabular}{|l|l|l|l|l|}
\hline $\begin{array}{l}\text { The light at the beginning and at the } \\
\text { end of the crossing }\end{array}$ & \multicolumn{2}{|l|}{ Number of pedestrians (\%) } & \multicolumn{2}{l|}{$\begin{array}{l}\text { Number of pedestrians who } \\
\text { created conflict situation (\%) }\end{array}$} \\
\hline Green - Green & 2188 & $(42.8 \%)$ & 0 & $(0.0 \%)$ \\
\hline Green - Red & 2029 & $(39.7 \%)$ & 4 & $(2.6 \%)$ \\
\hline Red - Red & 506 & $(9.9 \%)$ & 126 & $(81.3 \%)$ \\
\hline Red - Green & 386 & $(7.6 \%)$ & 25 & $(16.1 \%)$ \\
\hline$\Sigma$ & 5109 & $(100 \%)$ & 155 & $(100 \%)$ \\
\hline
\end{tabular}

During the survey some vehicle/pedestrian conflicts, caused by pedestrian were registered. Conflict situations were those: either pedestrian or a driver had to make a sudden change of their walking/driving, in order to avoid the accident. The highest number of pedestrians who created conflict situations are those who started and finished crossing during red light (81.3\%). Detailed structure of pedestrians who created conflict situation by gender, age, way of crossing, and light during the crossing is shown in Table 3. 


\section{Table 3}

The Structure of Pedestrian Offenders who Created Conflict Situations

\begin{tabular}{|c|c|c|c|c|c|c|c|c|}
\hline \multirow[b]{2}{*}{ Gender } & \multirow{2}{*}{$\begin{array}{l}\text { Light } \\
\text { The way of } \\
\text { crossing / } \\
\text { Age }\end{array}$} & \multicolumn{3}{|c|}{ Red - Red } & \multicolumn{3}{|c|}{ Red - Green } & \multirow[b]{2}{*}{$\Sigma$} \\
\hline & & Alone & Couple & Group & Alone & Couple & Group & \\
\hline \multirow{4}{*}{ Male } & $\begin{array}{l}\text { under } 30 \\
(\%)\end{array}$ & $\begin{array}{l}25 \\
(48.1 \%)\end{array}$ & $\begin{array}{l}12 \\
(23.1 \%)\end{array}$ & $\begin{array}{l}3 \\
(5.8 \%)\end{array}$ & $\begin{array}{l}7 \\
(13.4 \%)\end{array}$ & $\begin{array}{l}2 \\
(3.8 \%)\end{array}$ & $\begin{array}{l}3 \\
(5.8 \%)\end{array}$ & $\begin{array}{l}52 \\
(57.1 \%)\end{array}$ \\
\hline & $\begin{array}{l}\text { from } 30 \text { to } \\
50(\%)\end{array}$ & $\begin{array}{l}16 \\
(61.5 \%)\end{array}$ & $\begin{array}{l}4 \\
(15.3 \%)\end{array}$ & $\begin{array}{l}3 \\
(11.5 \%)\end{array}$ & $\begin{array}{l}1 \\
(3.8 \%)\end{array}$ & $\begin{array}{l}2 \\
(7.7 \%)\end{array}$ & $\begin{array}{l}0 \\
(0 \%)\end{array}$ & $\begin{array}{l}26 \\
(28.6 \%)\end{array}$ \\
\hline & $\begin{array}{l}\text { older than } \\
50(\%)\end{array}$ & $\begin{array}{l}10 \\
(76.9 \%)\end{array}$ & \begin{tabular}{|l} 
\\
$(15.4 \%)$ \\
\end{tabular} & $\begin{array}{l}0 \\
(0 \%)\end{array}$ & $\begin{array}{l}1 \\
(7.7 \%) \\
\end{array}$ & $\begin{array}{l}0 \\
(0 \%)\end{array}$ & $\begin{array}{l}0 \\
(0 \%)\end{array}$ & $\begin{array}{l}13 \\
(14.3 \%)\end{array}$ \\
\hline & $\begin{array}{l}\sum \mathrm{I} \\
(\%)\end{array}$ & $\begin{array}{l}51 \\
(56 \%) \\
\end{array}$ & $\begin{array}{l}18 \\
(19.8 \%) \\
\end{array}$ & $\begin{array}{l}6 \\
(6.6 \%)\end{array}$ & $\begin{array}{l}9 \\
(9.9 \%) \\
\end{array}$ & $\begin{array}{l}4 \\
(4.4 \%) \\
\end{array}$ & $\begin{array}{l}3 \\
(3.3 \%) \\
\end{array}$ & $\begin{array}{l}91 \\
(58.7 \%)\end{array}$ \\
\hline \multirow{4}{*}{ Female } & $\begin{array}{l}\text { under } 30 \\
(\%)\end{array}$ & $\begin{array}{l}20 \\
(45.5 \%)\end{array}$ & $\begin{array}{l}16 \\
(36.4 \%)\end{array}$ & $\begin{array}{l}3 \\
(6.8 \%)\end{array}$ & $\begin{array}{l}3 \\
(6.8 \%) \\
\end{array}$ & $\begin{array}{l}2 \\
(4.5 \%)\end{array}$ & $\begin{array}{l}0 \\
(0 \%)\end{array}$ & $\begin{array}{l}44 \\
(68.8 \%)\end{array}$ \\
\hline & $\begin{array}{l}\text { from } 30 \text { to } \\
50(\%)\end{array}$ & $\begin{array}{l}8 \\
(47 \%)\end{array}$ & $\begin{array}{l}2 \\
(11.8 \%)\end{array}$ & $\begin{array}{l}2 \\
(11.8 \%)\end{array}$ & $\begin{array}{l}3 \\
(17.6 \%)\end{array}$ & $\begin{array}{l}2 \\
(11.8 \%)\end{array}$ & $\begin{array}{l}0 \\
(0 \%)\end{array}$ & $\begin{array}{l}17 \\
(26.5 \%)\end{array}$ \\
\hline & $\begin{array}{l}\text { older than } \\
50(\%)\end{array}$ & $\begin{array}{l}1 \\
(33.3 \%)\end{array}$ & $\begin{array}{l}2 \\
(66.7 \%) \\
\end{array}$ & $\begin{array}{l}0 \\
(0 \%)\end{array}$ & $\begin{array}{l}0 \\
(0 \%)\end{array}$ & $\begin{array}{l}0 \\
(0 \%)\end{array}$ & $\begin{array}{l}0 \\
(0 \%)\end{array}$ & $\begin{array}{l}3 \\
(4.7 \%) \\
\end{array}$ \\
\hline & $\begin{array}{l}\sum \mathrm{II} \\
(\%)\end{array}$ & $\begin{array}{l}29 \\
(45.3 \%) \\
\end{array}$ & \begin{tabular}{|l|}
20 \\
$(31.2 \%)$ \\
\end{tabular} & $\begin{array}{l}5 \\
(7.8 \%) \\
\end{array}$ & \begin{tabular}{|l}
6 \\
$(9.4 \%)$ \\
\end{tabular} & $\begin{array}{l}4 \\
(6.3 \%) \\
\end{array}$ & $\begin{array}{l}0 \\
(0 \%) \\
\end{array}$ & $\begin{array}{l}64 \\
(41.3 \%) \\
\end{array}$ \\
\hline \multicolumn{2}{|l|}{$\begin{array}{l}\sum \mathrm{I}+\mathrm{II} \\
(\%)\end{array}$} & $\begin{array}{l}80 \\
(51.6 \%)\end{array}$ & $\begin{array}{l}38 \\
(24.5 \%)\end{array}$ & $\begin{array}{l}11 \\
(7.1 \%)\end{array}$ & $\begin{array}{l}15 \\
(9.7 \%)\end{array}$ & $\begin{array}{l}8 \\
(5.2 \%) \\
\end{array}$ & $\begin{array}{l}3 \\
(1.9 \%)\end{array}$ & $\begin{array}{l}155 \\
(100 \%)\end{array}$ \\
\hline
\end{tabular}

The probability of initiating a creating the conflict situation depends on a moment of red light crossing. The risk that pedestrians will initiate and create a conflict situation could be calculated by Eq. (1):

$\mathrm{R}=\frac{\operatorname{TiS}}{\operatorname{TiP}} \times 100 \%$,

where,

$R$ - is risk that pedestrians will create a conflict situation;
TiS - the number of pedestrians who crossed the pedestrian crossing in $i_{\text {th }}$ - red light interval and created conflict situation;

TiP - total number of pedestrians who crossed the pedestrian crossing in $i_{\text {th }}$ - red light interval.

The lowest probability that pedestrians will create conflict situation is in the first or in the last $5 \mathrm{~s}$ of red light. In other intervals there is higher probability of creating conflict situation (Fig. 3). 


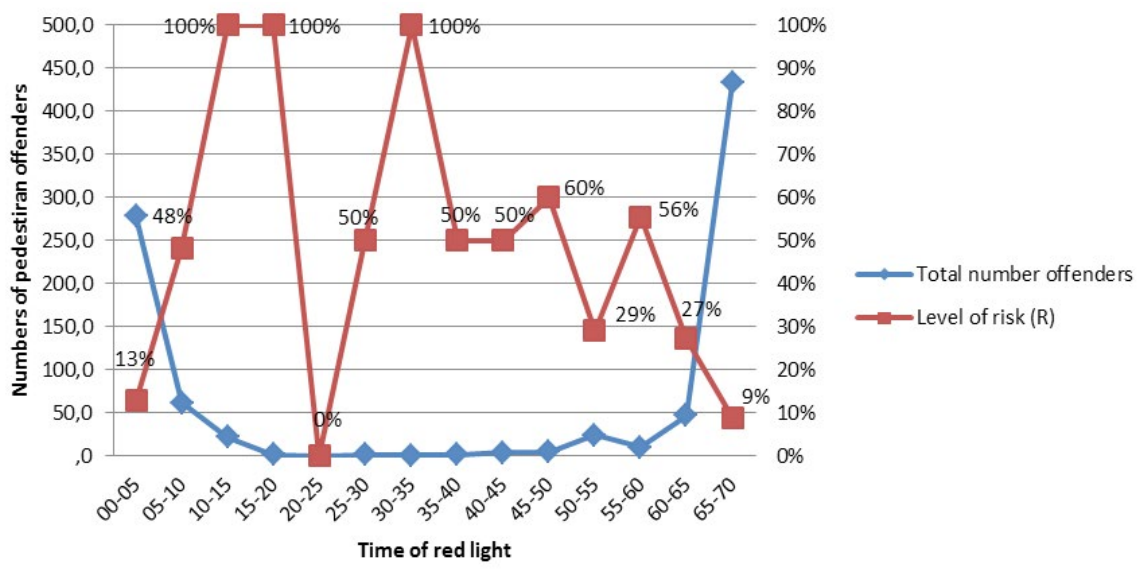

Fig. 3.

Pedestrians who Cross the Street during Red Light and the Level of Risk

Comparative analysis of number of pedestrian red light crossings and number of pedestrians who create conflict situation shows that the highest number of offenders cross the street during the red light intervals when the probability for creating conflict situation is lowest, because $r=-0,505$ $(\mathrm{p}=0,033)$. So, there is "negative medium correlation" between number of pedestrian red light offenders and the number of conflict situations. In other words, in period where pedestrians are less likely to cross the street during red light, the risk is higher and the highest number of accident could occur, and vice-versa.

\section{Discussion}

Results show that $17.5 \%$ of pedestrians cross during the red light, and there is a significant difference in the number of males and females who cross the street during red light (higher number of males start crossing during the red light, compared to females). Rosenbloom (2009) came to the similar conclusions. Pedestrians usually start crossing during the red light when being alone, which is conclusion similar to the one made by Keegan and O'Mahony (2003) and Rosenbloom (2009). The structure of pedestrians who create conflict situation shows that male pedestrians create more conflict situations than female pedestrians, and pedestrians both gender under 30 ages create significant more conflict situations than older pedestrians.

Research accepted that the highest probability for pedestrians to create conflict situations if they started and finished crossing during red light phase, but contrary, there were a significant number of conflict situations if pedestrians started crossing at red light phase and finished crossing at green phase. On the other hand, the analysis of the number of offenders shows that each fourth pedestrian who started and finished crossing during red light created conflict situations, while each fifteenth pedestrian who started crossing at red light phase and finished crossing at green phase were create conflict situations. 
The lowest probability for pedestrians to create conflict situations is when start crossing in the first or in the last period of 5 s of red light, but in other intervals this probability is much higher. Those pedestrians' behavior represents potential danger for vehicles that use the last seconds of their green light to enter the intersection. It is also noticed that males are less patient to wait for green light and they start to become offenders after 50s of waiting, and small number of pedestrians made red light crossing between 15 and $50 \mathrm{~s}$ of red light phase, so it could be concluded that $50 \mathrm{~s}$ is acceptable waiting time for pedestrians.

Considering previously done analysis, for concrete location it is necessary to shorten the pedestrian's red light phase at 50s and countdown displays additionally have to give text messages to pedestrians as well, because in the critical intervals (especially at the end of red light phase for pedestrians) pedestrians have to wait for a while and additional displays could give a message that vehicles could appear and not to start to crossing.

\section{Conclusion}

In low and middle income country there are significant problems in traffic safety, especially with pedestrian and with other vulnerable road users. The intersections are locations where the highest number of conflicts between pedestrians and vehicles occurs. Many measures are used for increasing pedestrian traffic safety. Among others, countdown displays are used, especially at the intersections. Most researches showed that counters have positive influence for pedestrian traffic safety, especially in reducing number of offenders. In this paper research indicated number of pedestrians who are offenders, and risk for pedestrian-vehicle accidents regard second after red light onset.

Research also showed that pedestrians usually cross at red light during the last seconds of red light phase, or in the first seconds of red light phase, while the most conflict risk is in other periods of red light phase. The negative consequence of using the countdown displays is increasing number of pedestrians who are offenders, because they start crossing about start or end of red light phase. On the other hand, at pedestrian crossing with countdown display information about time to start or finish red light phase are given to pedestrians, so they usually start cross besides the red light on. Those pedestrians take greater risk besides information gotten from countdown display.

The total number of male and female pedestrians showed that there is no significant difference between number of male and female pedestrians, but the male pedestrians more significant crossed at red light than female pedestrians, and male pedestrians created more significant conflict situations than female pedestrians. The pedestrians both gender under 30 ages crossed at red light more often than older pedestrians, and they created significant more conflict situations than older pedestrians. The pedestrians both genders crossed at red light usually when they begin alone and they created the highest number of conflict situations compare than pedestrians in couple or group. Considering previously done analysis, the male pedestrians under 30 ages being alone when crossing, has the highest probability to create conflict situation, and to this group of pedestrians adequate countermeasures have to be implemented (i.e. road safety campaigns, etc.). 
For further development of method for analyzing pedestrians' behavior and road accident risk at signalized intersection, it is necessary to analyze more and other types of intersections. Also, it would be necessary that conflict situations be considered more in details such as highly, medium or less dangerous situations, in order to be more precise in calculating risk. Pedestrians' behavior have to be analyzed also due to different intensity of traffic flow, different intensities of pedestrian flows, and these parameters also have to be included in analysis and for further development of measures.

\section{References}

Allsbrook, L.E. 1999. Pedestrian Signal Countdown Device, ITE Journal, Enhancing Transportation Safety in the 21st Century, ITE International Conference, Florida, Held: 28-31 March 1999, Washington DC, USA. 69(3): $15 \mathrm{p}$.

Antić, B.; Vujanić, M.; Lipovac, K.; Pešić, D. 2011. Estimation of the traffic accidents costs in Serbia by using dominant costs model, Transport. DOI: http:// dx.doi.org/10.3846/16484142.2011.635425, 26(4): 433-440.

Baass, K.G. 1989. Review of European and North American practice of pedestrian signal timing. Prepared for RTACAnnual Conference Calgary, Alberta, September 17-21.

Díaz, E.M. 2002. Theory of planned behavior and pedestrians' intentions to violate traffic regulations, Transportation Research Part F: Traffic Psychology and Behaviour. DOI: http://dx.doi.org/10.1016/S13698478(02)00015-3, 5(3): 169-175.

Druilhe, M.; Khoudour, L. 1987. Pietons: une si longue attente. Association pour le Dèveloppement des Techniques de Transport et d'Environnement et de Circulation, TEC No. 84/85, 36-40.
Eccles, K.A.; Tao, R.; Mangum, B.C. 2004. Evaluation of Pedestrian Countdown Signals in Montgomery County, Maryland. Presented at the Transportation Research Board $83^{\text {rd }}$ Annual Meeting, Washington, D.C., USA.

Guo, H.; Gao, Z.; Yang, X.; Jiang, X. 2011. Modeling Pedestrian Violation Behavior at Signalized Crosswalks in China: A Hazards-Based Duration Approach, Traffic Injury Prevention. DOI: http://dx.doi.org/10.1080/153 89588.2010.518652, 12(1): 96-103.

Huang, H.; Zeeger, C. 2000. The Effects of Pedestrian Countdown Signals in Lake Buena Vista. University of North Carolina Highway Safety Research Center for Florida Department of Transportation, November.

Keegan, O.; O’Mahony, M. 2003. Modifying Pedestrian Behavior, Transportation Research Part A: Policy and Practice. DOI: http://dx.doi.org/10.1016/S0965-8564(03)000612, 37(10): 889-901.

Lipovac, K.; Vujanić, M.; Marić, B.; Nešić, M. 2013. Pedestrians' Behavior at Signalized Pedestrian Crossings, Journal of Transportation Engineering. DOI: http://dx.doi.org/10.1061/(ASCE)TE.19435436.0000491, 139(2): 165-172.

Markowitz, F.; Sciortino, S.; Lucero, J.F.; Bond, Y.M. 2006. Pedestrian Countdown Signals: Experience with an Extensive Pilot Installation, Institute of Transportation Engineers, ITE Journal, 76(1): 43-48.

Martin, A. 2006. Factors Influencing Pedestrian Safety: A Literature Review. TRL Limited PPR 241, London.

Pešić, D.; Vujanić, M.; Lipovac, K.; Antić, B. 2012. An integrated method of identifying and ranking danger spots for pedestrians on microlocation, Transport. DOI: 10.3846/16484142.2012.664826, 27(1): 49-59.

Rosenbloom, T. 2009. Crossing at a red light: Behavior of individuals and groups, Transportation Research Part F: Traffic Psychology and Behaviour. DOI: http://dx.doi. org/10.1016/j.trf.2009.05.002, 12(5): 389-394. 
Singer, J.P.; Lerner, N.D. 2005. Countdown Pedestrian Signals: A Comparison of Alternative Pedestrian Change Interval Displays. Final Report, Federal Highway Administration, Rockville.

Vujanić, M.; Lipovac, K.; Jovanović, D.; Pešić, D.; Antić, B. 2013. 'Bottom-up" and 'top-down" approach for defining road safety strategy - case study: city of Belgrade, International Journal for Traffic and Transport Engineering. DOI: http://dx.doi.org/10.7708/ ijtte.2013.3(2).07, 3(2): 185-203.

World Health Organization. 2009. Global status report on road safety: time for action. World Health Organization, Geneva. 